\title{
Rates of Major Obstetrical Complications and Their Burden on Maternal Mortality in an Urban Health Center in Senegal
}

\author{
Delali David*, Moussa Diallo, Mame Diarra Ndiaye Gueye Mamour Gueye, Magatte Mbaye, Alassane Diouf and \\ Jean-Charles Moreau
}

Gynecologic and Obstetric Clinic, Aristide Teaching Hospital, Cheikh Anta Diop University, Sénégal

Submission: November 21, 2018 ; Published: December 13, 2018

*Corresponding author: Delali David, Gynecologic and Obstetric Clinic, Aristide Teaching Hospital, Cheikh Anta Diop University, Sénégal

\begin{abstract}
Objective: The evaluation of the rate of major obstetric complications and their impact on maternal mortality highlights certain factors favoring their occurrence. The goal of this study was to gather facts and figures to strengthen health structures and reduce maternal mortality in the urban suburbs of Dakar.

Material and method: This was a transversal, retrospective and prospective study that evaluated all women admitted at the Philippe Maguilen Senghor Health Center (a level 2-health center) in Dakar. The study covered a 66-month period from January 1, 2012 to June 30, 2017 and aimed at assessing the rate of major obstetric complications and their impact on maternal mortality. The target group included in our sample were women with a complete medical record. Those whose files were not complete were not included in the study.

Results: Our study involved 25,905 patients aged between 11 and 53 years old, of which 16,001 were multiparous and 9,904 were primiparous. We found in $14.1 \%$ of our patients serious obstetric complications. These complications were dominated by dystocia (9.3\%); severe pre-eclampsia (SPE), (2.9\% of cases), followed by antepartum haemorrhage (APH) (2.1\% of cases). Furthermore, the main indications for caesarean section were fetal distress (24.5\%), dynamic dystocia (20.6\%) and scarred uterus (7.9\%). In our cohort, $21.6 \%$ were transferred from another hospital. Upon admission at the center, $50.2 \%$ of the women were in latency phase of the labor, $39.7 \%$ in the active phase and $8.9 \%$ were not begined the labor. With respect to prenatal care, only $52.8 \%$ had completed her prenatal visits according to the national guidelines. In our study, pregnancies were full term in $89.8 \%$.
\end{abstract}

Conclusion: The evaluation of the factors enabling the occurrence of major obstetric impediments at country level, but also on the continent, would allow for a decrease in the incidence of these complications. The challenge posed by major obstetric complications must be addressed to reduce maternal morbidity and mortality in order to reach the third Sustainable Development Goal (SDG), of good health and wellbeing, in Senegal by 2030 .

Keywords: Obstetric complications; Major obstetric complications; Maternal mortality

Abbreviatations: SDG: Sustainable Development Goal; WHO: World Health Organization; PMSH: Philippe Maguilen Senghor Hospital; ANC: Antenatal Care Coverage; APH: Antepartum Haemorrhage; HPP: Postpartum Haemorrhage; SPE: Severe Pre-eclampsia; RU: Ruptured Uterus

\section{Introduction}

Maternal mortality is a hot topic in the world and in subSaharan Africa in particular. Over the last three decades, estimates by the World Health Organization (WHO) have indicated that more than half a million women die each year from pregnancy and childbirth-related causes [1-3]. The overall objective of our study was to evaluate the rate of major obstetric complications and their impact on maternal health at the Philippe Maguilen Senghor Hospital (PMSH) in Dakar, a level 2 structure in the health pyramid of Senegal. The specific objectives were to identify obstetric complications and major obstetric complications, to determine the specific lethality by major obstetric complication, and to come up with recommendations for better management of these hitches.

\section{Methodologie}

\section{Framework of study}

Our study was conducted at the Philippe Maguilen Senghor Hospital of the West District of Dakar located in the western suburbs of Dakar. The health system in Senegal is structured in three different type of health facilities: health posts, level 1 and 2 health centers and finally, public hospitals. The PMSH is a level 2 
health center. It does not have the performance of a hospital but surgical interventions are performed there. Teams of specializing obstetrical gynecologists, midwives and nurses provide continuous, Obstetric Emergency Neonatal and gynecological care. The on-call duties are carried under the supervision of a senior specialist in Gynecology-Obstetrics [4].

\section{Evaluation of the data}

The data for this study was collected over a period of 66 months, from January 1, 2012 to June 30, 2017.

We performed a first retrospective registration period of medical records from 2012 to 2015; then a second period of prospective data recording for the years 2016 and 2017.

\section{Data collection}

The data was entered into our E-perinatal computer database and then extracted and analyzed first on Microsoft Excel 2016, then on SPSS 24, Windows version [5].

\section{Definition of the studied parameters}

The parameters that were analysed to conduct this study were as follows: age of the patient, parity, mode of admission (home, transfer), stage of labor upon admission, antenatal care coverage (ANC) of pregnancy, quality of the uterus (uterus new or scarred), term of pregnancy (full term pregnancy, early or post-term), type of pregnancy (mono-fetal or multiple), induction of labor (spontaneous pregnancy labor, induced or caesarean-section before labor), type of fetal presentation, Apgar score at first minute and major direct obstetric complications .
Direct obstetric complications are complications that occur during pregnancy, childbirth, or postpartum [6-9]. This is [10]: antepartum and postpartum haemorrhage; prolonged labor/dystocia; puerperal infection; complications of abortion (hemorrhagic, infectious and toxic complications), severe pre-eclampsia and eclampsia, ectopic pregnancy, and ruptured uterus. The women included in our sample were those with a complete medical record containing all the parameters studied. The women whose file were not complete and the unusable data were not included.

\section{Result}

\section{General result}

Our study involved a sample of 25905 patients aged from 11 to 53 with an average age of 27 years. More than half (54.5\%) were aged 20 to 29 years. The maximum parity found was 13 and represented $1 \%$ of our patients; $38.2 \%$ were primiparous and $61.8 \%$ were multiparous. The admitted patients came from their home in $78.4 \%$ of the cases and $21.6 \%$ were transferred from another health facility. At admission, $50.2 \%$ of them were in labor latency phase and $39.7 \%$ in active phase; $8.9 \%$ were not working and $1.2 \%$ were admitted after delivery. Our study showed that $0.5 \%$ of patients had no NPC and $52.8 \%$ had at least four NPCs in accordance with WHO requirements [1,5]. Of all our patients, $14.1 \%$, or 3664 , had a serious obstetric complication. These complications were dominated by dystocia estimated at 9.3\%; Severe preeclampsia (SPE) was in second place with $2.9 \%$ of cases followed by antepartum haemorrhage (APH) with $2.1 \%$ of cases (Figure 1).

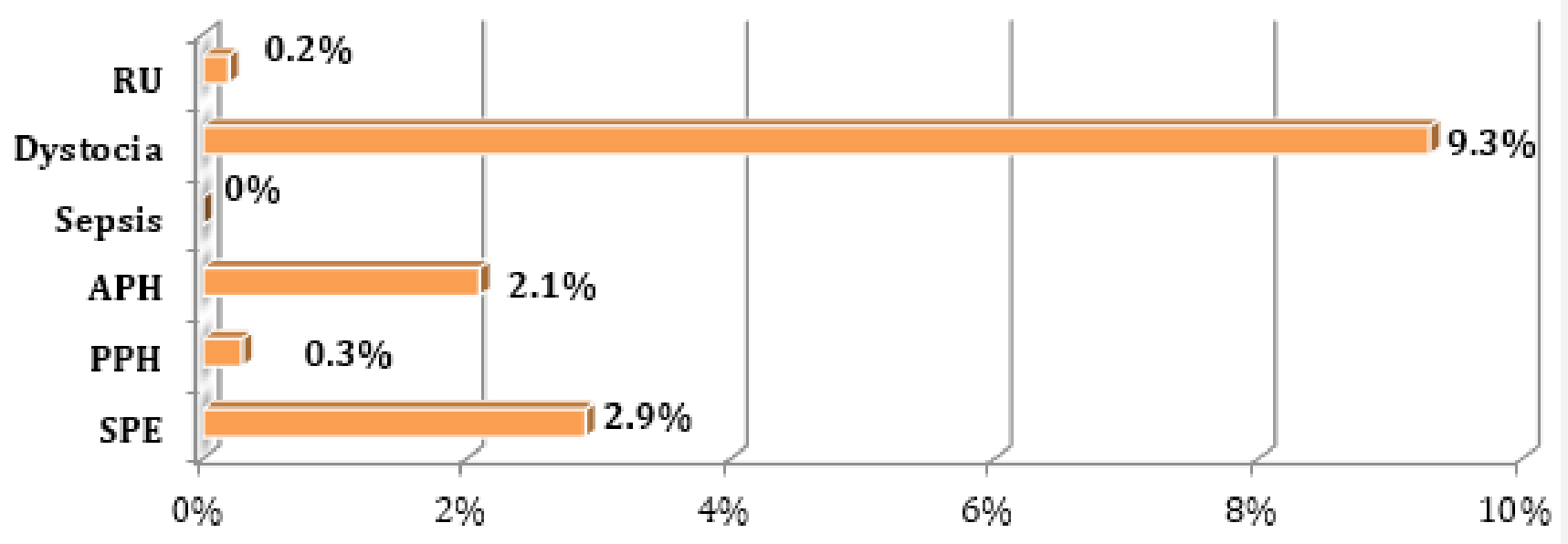

Figure 1: Rates of major obstetric complications at the Philippe Maguilen Senghor Health Center in Dakar from 2012 to 2017 ( $N=25905)$. APH : antepartum haemorrhage.

HPP : postpartum haemorrhage.

SPE: severe pre-eclampsia.

$\mathrm{RU}$ : ruptured uterus.

\section{The different major obstetric complications according} to the studied parameters

Parity: A serious obstetric complication was diagnosed in $12.2 \%$ of multiparous patients and $17.3 \%$ in primiparous women. Dystocia was the dominant complication occurring in $7.2 \%$ of cases in multiparous women and $12.5 \%$ of cases in primiparous ones. There were 40 cases of ruptured uterus in multiparous women and 3 cases in primiparous women. Whatever the parity, the most frequent complications were, in descending order, dystocia, then SPE and APH (Figure 2 \& 3). 


\section{Journal of Gynecology and Women's Health}

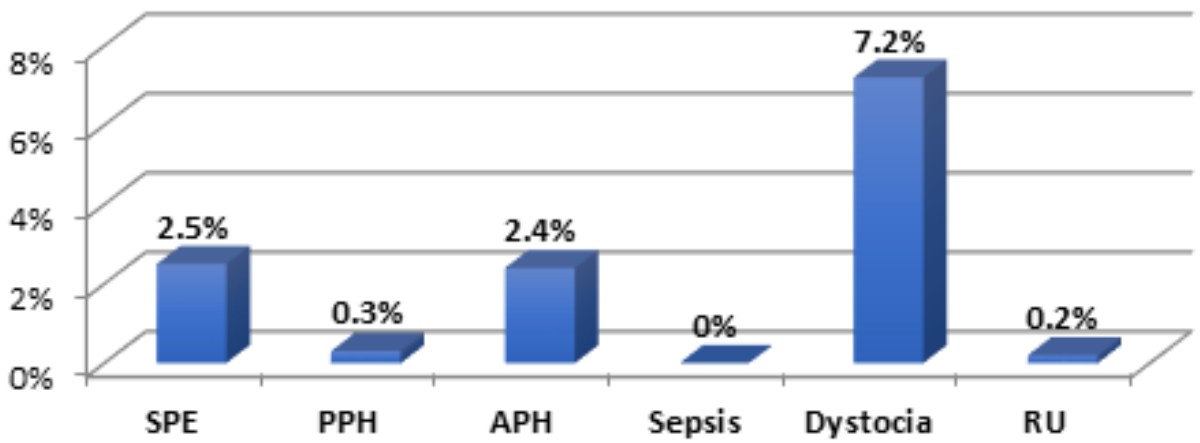

Figure 2: Rates of major obstetric complications in multiparous patients at the Philippe Maguilen Senghor Health Center in Dakar from 2012 to 2017 ( $\mathrm{N}=16001)$.

$\mathrm{APH}$ : antepartum haemorrhage.

HPP : postpartum haemorrhage.

SPE: severe pre-eclampsia.

$\mathrm{RU}$ : ruptured uterus.

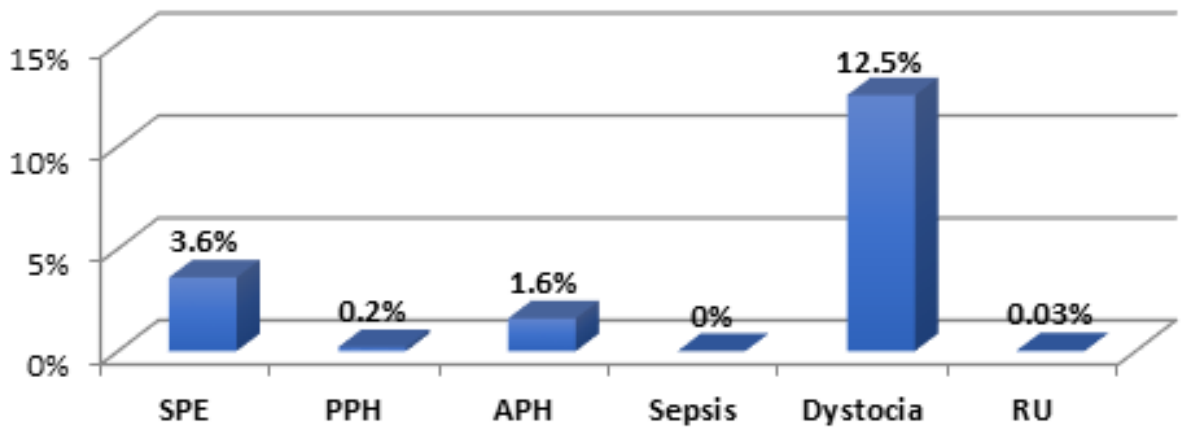

Figure 3: Rates of major obstetric complications among primiparous patients at the Philippe Maguilen Senghor Health Center in Dakar from 2012 to 2017 ( $\mathrm{N}=9901)$.

$\mathrm{APH}$ : antepartum haemorrhage.

HPP : postpartum haemorrhage.

SPE: severe pre-eclampsia.

$\mathrm{RU}$ : ruptured uterus.

Mode of admission: According to the mode of admission, 9.7\% of patients coming from their home had an obstetric complication compared to $30.4 \%$ for patients from a transfer. The most common complication was dystocia, with respectively $6.3 \%$ for patients coming from home and $20.1 \%$ for transfer patients (Figures 4 \& 5)

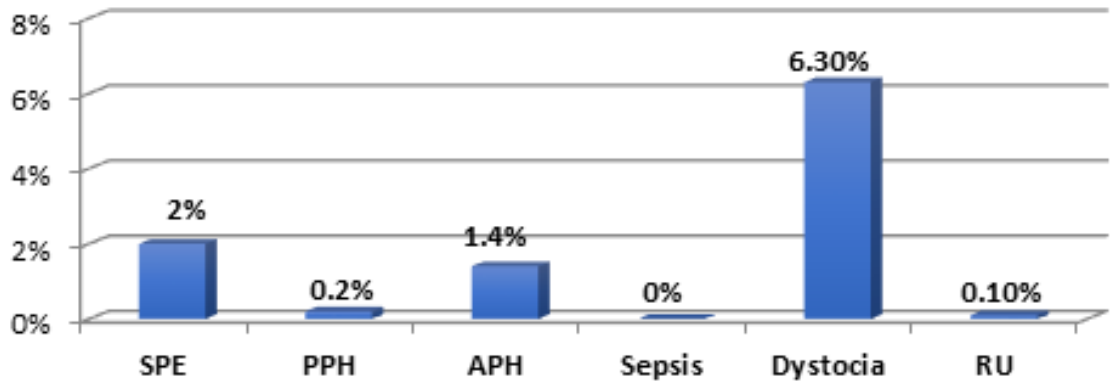

Figure 4: Rates of major obstetric complications in patients coming from their homes at the Philippe Maguilen Senghor Health Center in Dakar from 2012 to 2017 ( $N=20312)$.

APH : antepartum haemorrhage.

HPP : postpartum haemorrhage.

SPE: severe pre-eclampsia.

$\mathrm{RU}$ : ruptured uterus. 


\section{Journal of Gynecology and Women's Health}

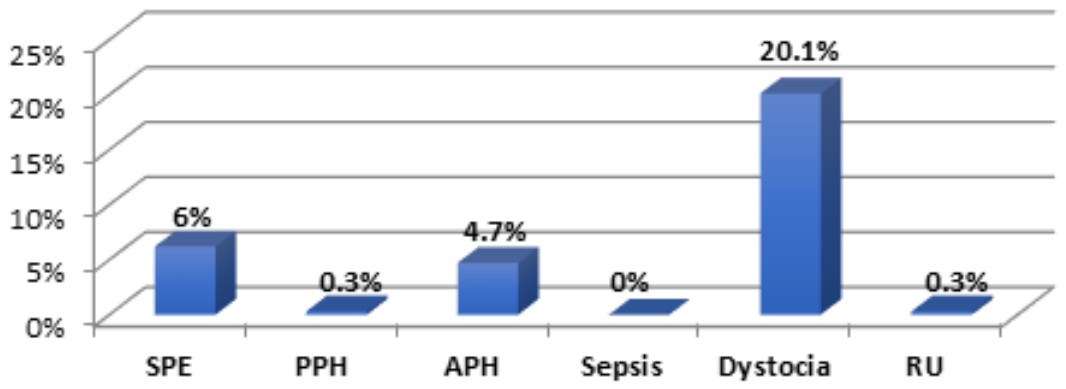

Figure 5: Rates of major obstetric complications in patients from a transfer to the Philippe Maguilen Senghor Health Center in Dakar from 2012 to 2017 ( $N=5593)$.

APH : antepartum haemorrhage.

HPP : postpartum haemorrhage.

SPE: severe pre-eclampsia.

$\mathrm{RU}$ : ruptured uterus.

Term of pregnancy: Out of the patients in our sample, $21.9 \%$ of those who had obstetric complications had early term pregnancies, $13.6 \%$ had a full term pregnancy and $13.4 \%$ cases $(n=3364)$ were prolonged or postterm pregnancies. None of the early term pregnancies were correlated with sepsis; $9.5 \%$ of them had a SPE and 8.9\%a AHP (Figure 6). Among the full term pregnancies, none were correlated with sepsis. 9.6\% had dystocia and $2.4 \%$ had a SPE (Figure 7). Among late term and postterm pregnancies, none were correlated with sepsis. 9.2\% had dystocia and 3\% had a SPE. Besides, no case of RU were registered (Figure 8).

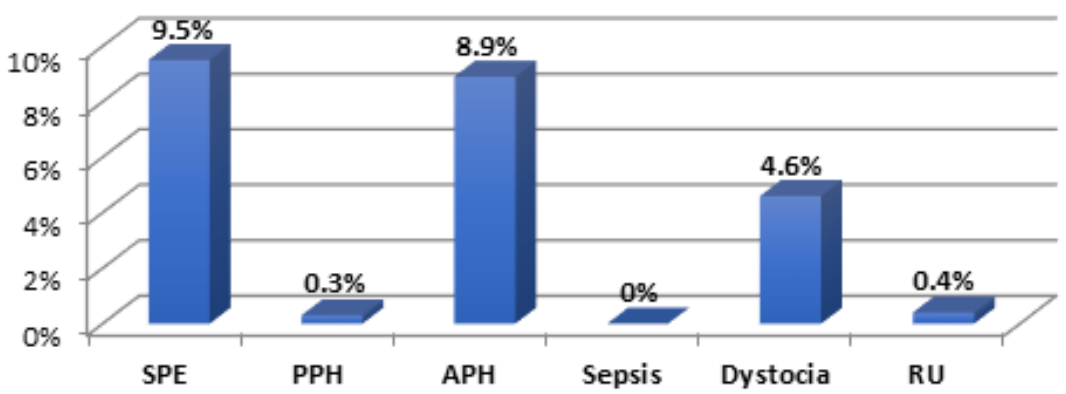

Figure 6: Rates of major obstetric complications among early term pregnancies at the Philippe Maguilen Senghor Health Center in Dakar from 2012 to $2017(\mathrm{~N}=1706)$.

APH : antepartum haemorrhage.

HPP : postpartum haemorrhage.

SPE: severe pre-eclampsia.

$\mathrm{RU}$ : ruptured uterus.

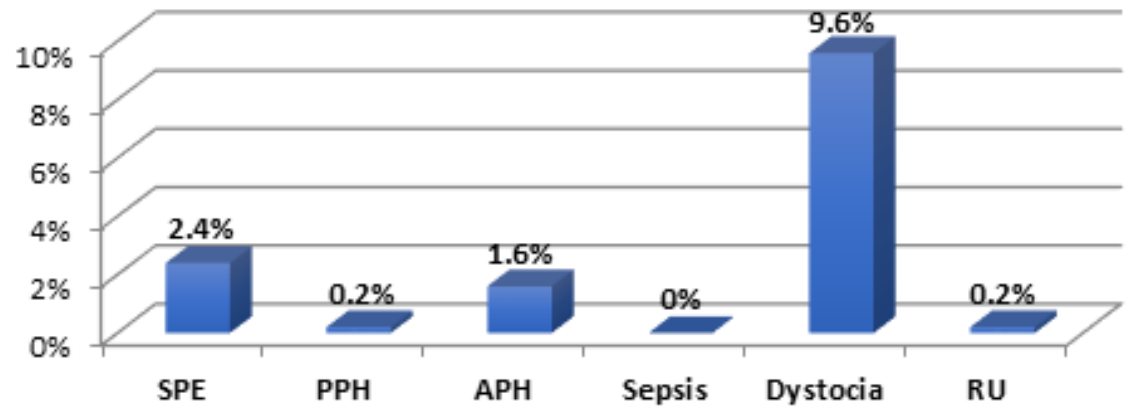

Figure 7: Rates of major obstetric complications among full term pregnancies at the Philippe Maguilen Senghor Health Center in Dakar from 2012 to 2017 ( $N=23252)$.

$\mathrm{APH}$ : antepartum haemorrhage.

HPP : postpartum haemorrhage.

SPE: severe pre-eclampsia.

$\mathrm{RU}$ : ruptured uterus. 


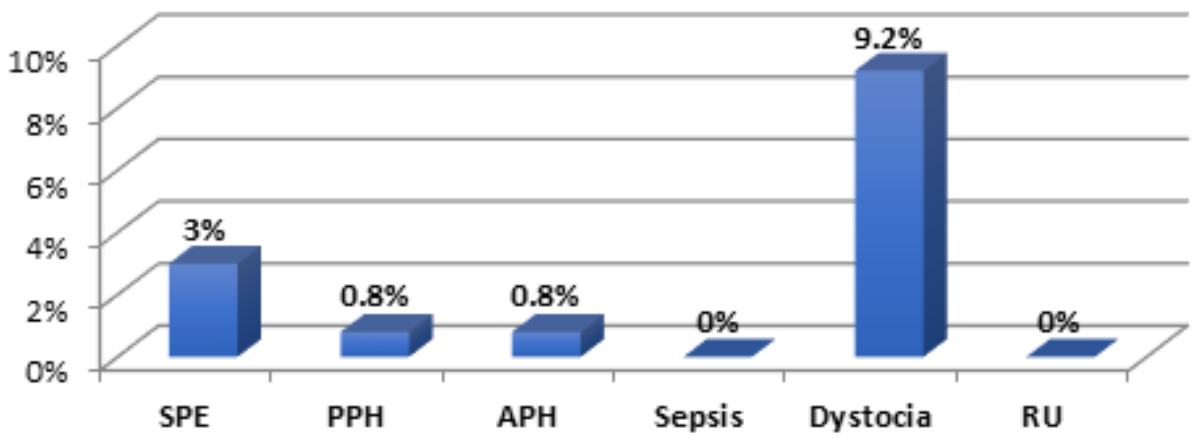

Figure 8: Rates of major obstetric complications among post-term pregnancies at the Philippe Maguilen Senghor Health Center in Dakar from 2012 to 2017 ( $\mathrm{N}=947$ ).

$\mathrm{APH}$ : antepartum haemorrhage.

HPP : postpartum haemorrhage.

SPE: severe pre-eclampsia.

$\mathrm{RU}$ : ruptured uterus.

Type of presentation: In 14\% of cephalic presentations, we observed a major obstetric complication. Breech presentations in $17.3 \%$ of cases were burdened with obstetric complication and in $16.5 \%$ of cases with cross-sectional presentations. In cephalic presentation, dystocia was diagnosed in $9.1 \%$ of cases and SPE in $2.9 \%$ of cases. No sepsis cases were revealed (Figure 9). In a breech presentation, dystocia was diagnosed in $12.4 \%$ of cases; SPE in $2.8 \%$ of cases. No cases of sepsis had been revealed (Figure 10). In front of a transversal presentation, dystocia was diagnosed in $6.6 \%$ of cases; APH in the same proportions. No cases of sepsis or PPH were revealed (Figure 11).

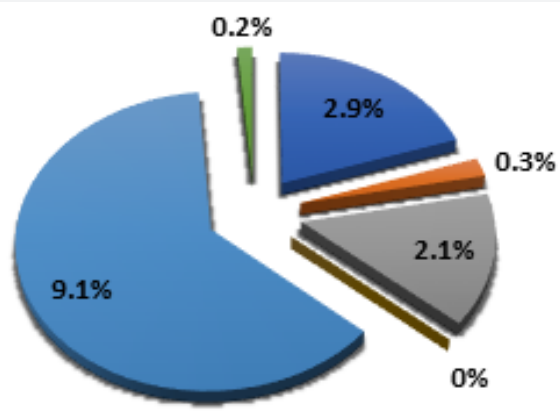

WPE
PPH
APH
= SEPSIS
DYSTOCIA
RU

Figure 9: Rates of major obstetric complications among cephalic presentations at the Philippe Maguilen Senghor Health Center in Dakar from 2012 to 2017 ( $N=24421)$.

APH : antepartum haemorrhage.

HPP : postpartum haemorrhage.

SPE: severe pre-eclampsia.

$\mathrm{RU}$ : ruptured uterus.

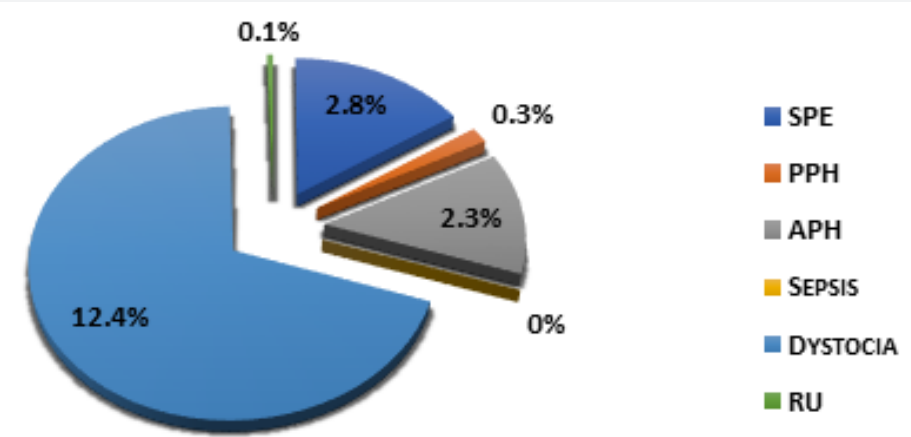

Figure 10: Rates of major obstetric complications among breech presentations at the Philippe Maguilen Senghor Health Center in Dakar from 2012 to $2017(N=1363)$.

APH : antepartum haemorrhage.

HPP : postpartum haemorrhage.

SPE: severe pre-eclampsia.

$\mathrm{RU}$ : ruptured uterus. 


\section{Journal of Gynecology and Women's Health}

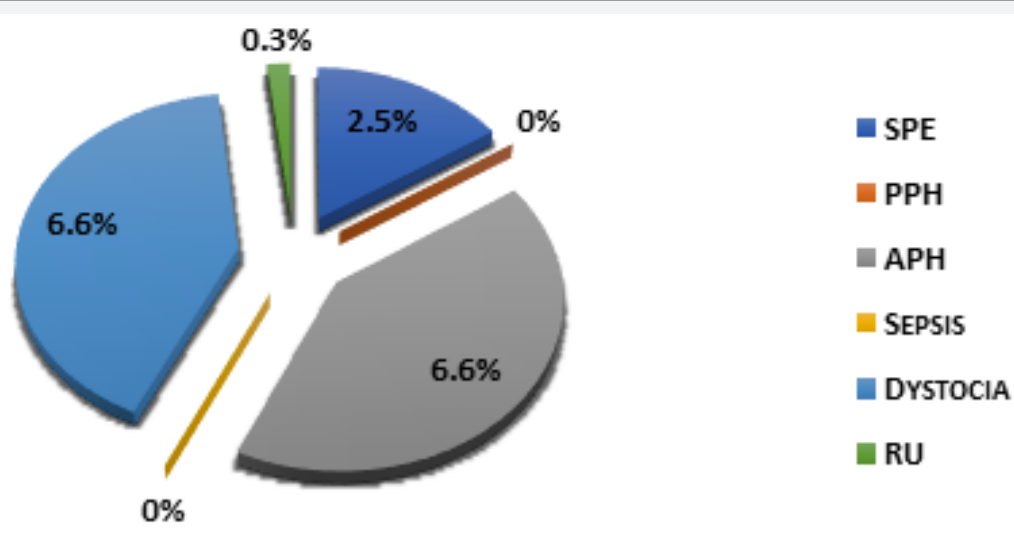

Figure 11: Rates of major obstetric complications among cross-sectional presentations at the Philippe Maguilen Senghor Health Center in Dakar from 2012 to $2017(\mathrm{~N}=121)$.

$\mathrm{APH}$ : antepartum haemorrhage.

HPP : postpartum haemorrhage.

SPE: severe pre-eclampsia.

$\mathrm{RU}$ : ruptured uterus.

Delivery route: Our study found $45.2 \%$ of major obstetric complications among patients who had a caesarean section and $2.1 \%$ in patients with vaginal delivery. Caesareans were performed for dystocia in $31.7 \%$ of cases, $7.9 \%$ of cases for SPE in and for APH in $6.7 \%$ (Figure 12). For vaginal deliveries, a proportion of $1 \%$ of severe pre-eclampsia was 186 cases. 9 cases of RU were found (Figure 13).

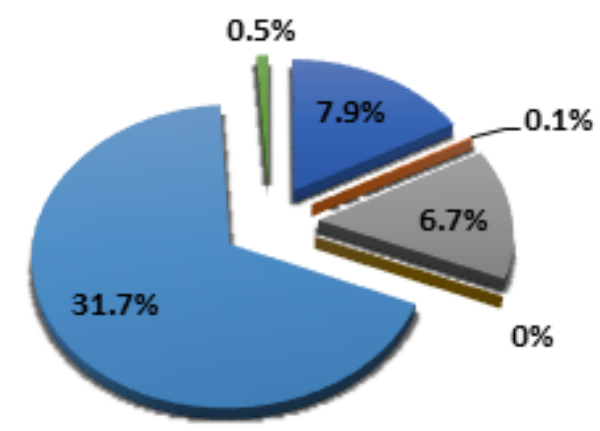

SPE
PPH
APH
SEPSIS
DYSTOCIA
RU

Figure 12: Rates of major obstetric complications among patients who had a cesarean section at the Philippe Maguilen Senghor Health Center in Dakar from 2012 to $2017(\mathrm{~N}=7250)$.

APH : antepartum haemorrhage.

HPP : postpartum haemorrhage.

SPE: severe pre-eclampsia.

$\mathrm{RU}$ : ruptured uterus.

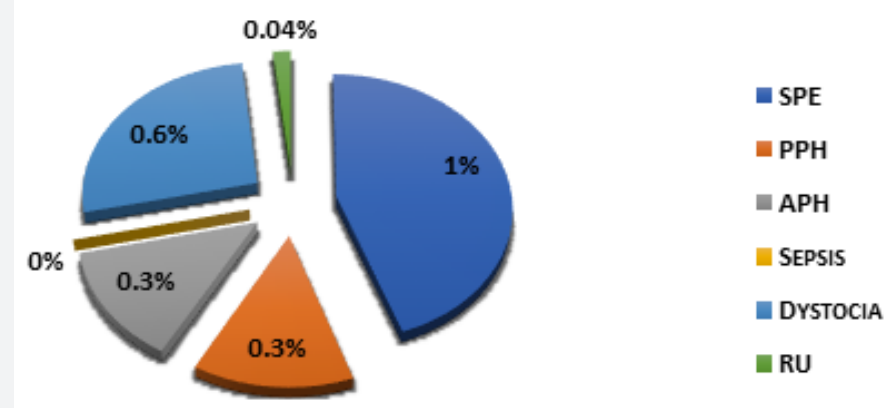

Figure 13: Rates of major obstetric complications among patients who received vaginal deliveries at the Philippe Maguilen Senghor Health Center from 2012 to 2017 ( $N=18655)$.

$\mathrm{APH}$ : antepartum haemorrhage.

HPP : postpartum haemorrhage.

SPE: severe pre-eclampsia.

$\mathrm{RU}$ : ruptured uterus. 


\section{Journal of Gynecology and Women's Health}

Apgar score: A major obstetric complication was associated with an Apgar score greater than or equal to 7 in $12.3 \%$ of cases $(n=22284)$. When the score was less than 7 , a major obstetric complication was present in $25.5 \%$ of cases $(n=3621)$. The main serious obstetric complications that were found when an Apgar score was greater than 7 were dystocia (8.9\% of cases) and SPE (2.5\% of cases) (Figure 14). When the Apgar score was less than 7 , the obstetric complications that were correlated were mainly dystocia (9.3\%), APH (9\%) and SPE (5.8\%) (Figure 15).

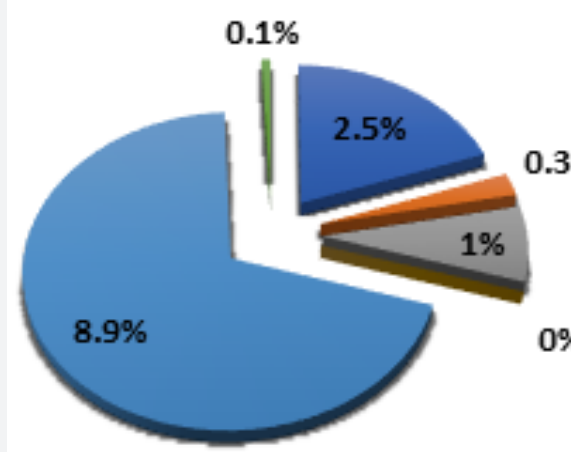

GPE
PPH
APH
SEPSIS
DYSTOCIA
RU

Figure 14: Rates of major obstetric complications among patients whose newborns have an Apgar score greater than 7 at the Philippe Maguilen Senghor Health Center in Dakar from 2012 to 2017 ( $N=22284$ ).

APH : antepartum haemorrhage.

HPP : postpartum haemorrhage.

SPE: severe pre-eclampsia.

$\mathrm{RU}$ : ruptured uterus.

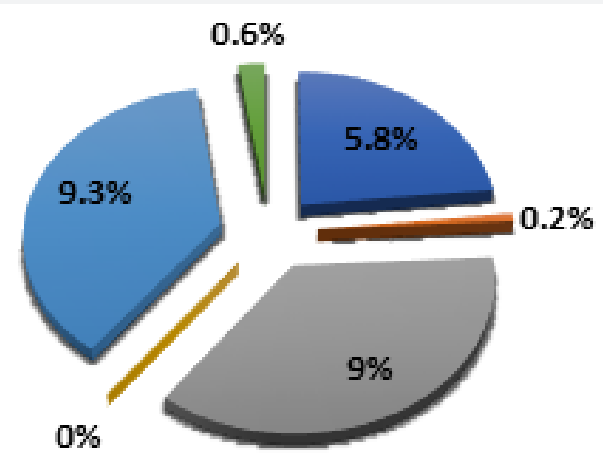

SPE
PPH
APH
SEPSIS
DYSTOCIA
RU

Figure 15: Rates of major obstetric complications among patients whose newborns have an Apgar score of less than 7 at the Philippe Maguilen Senghor Health Center in Dakar from 2012 to 2017 ( $N=3621)$.

$\mathrm{APH}$ : antepartum haemorrhage.

HPP : postpartum haemorrhage.

SPE: severe pre-eclampsia.

$\mathrm{RU}$ : ruptured uterus.

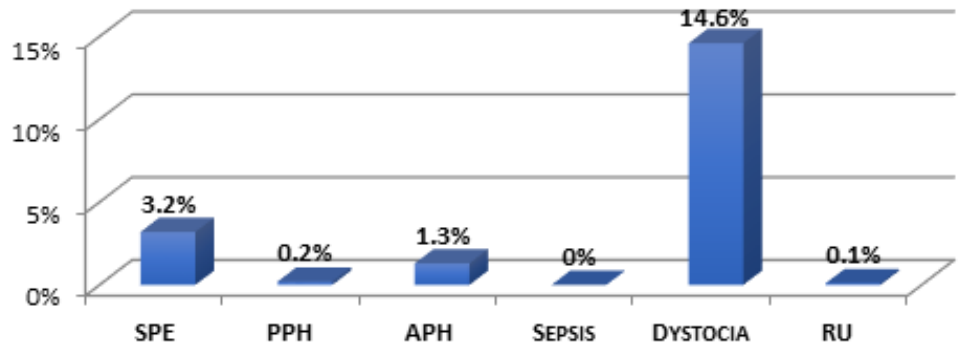

Figure 16: Rates of major obstetric complications among adolescent patients at the Philippe Maguilen Senghor Health Center in Dakar from 2012 to $2017(\mathrm{~N}=2616)$.

APH : antepartum haemorrhage.

HPP : postpartum haemorrhage.

SPE: severe pre-eclampsia.

$\mathrm{RU}$ : ruptured uterus. 
Patient's age: In adolescent patients received in the structure, dystocia was the main objectified obstetric complication and accounted for $14.6 \%$ of cases (Figure 16). In adult patients, dystocia was also the major complication and accounted for $8.7 \%$ of cases (Figure 17).

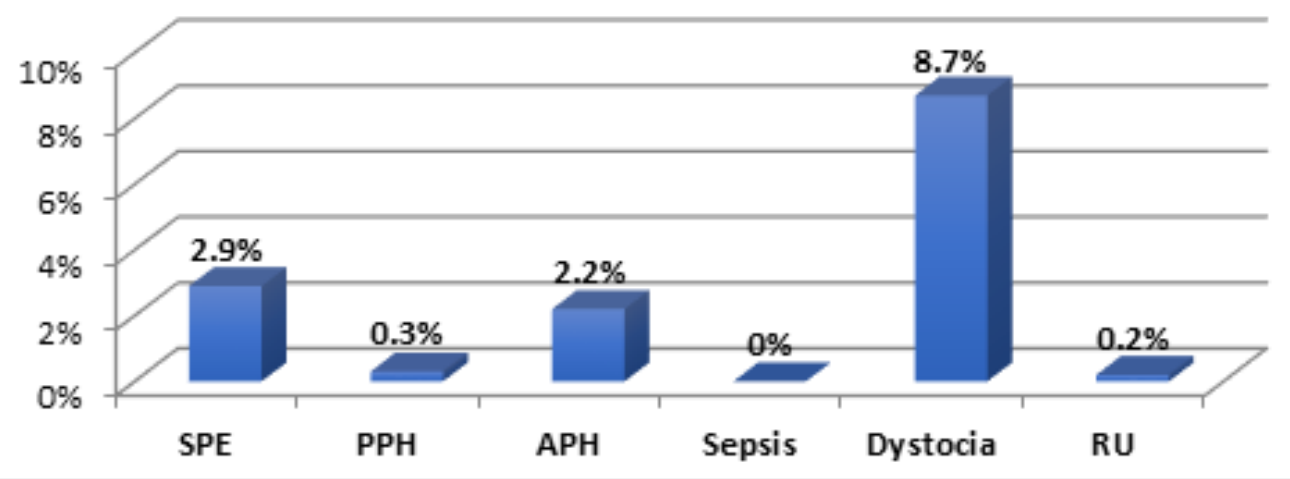

Figure 17: Rates of major obstetric complications among adult patients at the Philippe Maguilen Senghor Health Center in Dakar from 2012 to $2017(\mathrm{~N}=23289)$.

APH : antepartum haemorrhage.

HPP : postpartum haemorrhage.

SPE: severe pre-eclampsia.

$\mathrm{RU}$ : ruptured uterus.

\section{Discussion}

The results of our study have shown that it is important to assess the proportion of major causes of maternal deaths in order to identify them formally and thus better manage them. It is not enough to have the figures of maternal mortality, we must identify the deep factors that led to death and understand their mode of occurrence [6].

\section{Severe pre-eclampsia and eclampsia}

The occurrence of a SPE in our study was evaluated at $2.9 \%$ of cases. Eclampsia accounted for $1.6 \%$ of caesarean section indications at PMS Hospital. This rate is lower than that found by WHO in 2000 on the African continent, where the rate of severe complications of hypertension was estimated at 9.6\% [11,12]. In 2005 , the rate of pre-eclampsia and eclampsia in the world was $3.2 \%$ of live births [3].

We found that SPE occurred more often with primiparous patients $(3.6 \%)$ than in multiparous ones $(2.5 \%)$, and that in most cases this was a transfer patient $(6.2 \%)$ whose pregnancy was not a full term (9.5\%). Besides, the delivery route was predominantly cesarean section; and the assessment of the condition of the newborn most often associated with a score below 7 (5.8\%). However, there is no influence of the type of presentation or the age of the parturient on the occurrence of the SPE. These results prove that with political will and adequate awareness of the population, certain factors can be prevented. In fact, close monitoring with quality CPNs allows the early detection of specifics pathologies. Similarly, the quality of health structures significantly improves the management of pathological cases.

\section{Postpartum haemorrhage}

The occurrence of PPH in our study was evaluated at $0.30 \%$ of cases. Among the causes of haemorrhages, HPP is the one that causes the highest death rates in the world. It was estimated at $10.5 \%$ of all pregnancies in the world in 2005 [3,11,12]. This highlights the clear improvement of the health services in Senegal and the PMSH in particular with regard to this obstetric complication. Our study found that PPH was more common when pregnancy was late term or postterm (0.80\%), compared to $0.30 \%$ when pregnancy was early term and $0.20 \%$ when full term pregnancy. This result highlights the importance of NPC and early surveillance of parturients in order to know the correct term of their pregnancies. In addition, the follow-up of patients by competent medical personnel allows the appropriate decision-making, at the opportune moment by induction of labor or caesarean section if necessary. Similar rates of HPP occur regardless of parity, admission pattern, or age of the patient.

Our results highlight the need to continue to sensitize populations for early consultation, at early stage of their pregnancy, in health facilities. Therefore, it is also necessary to have a quality staff with a technical platform that can provide precise dating of pregnancies in order to take the appropriate measures to avoid postterm pregnancy and to take care of the HPP if necessary.

\section{Antepartum haemorrhage}

In our study, the occurrence of APH was estimated at $2.9 \%$. The multicenter survey on maternal mortality (MOMA study), conducted from 1994 to 1996 mainly in the capitals of six African countries (Burkina Faso, Ivory Coast, Mali, Mauritania, Niger and Senegal), gave an estimation of APH rates 20 -fold higher the equivalent of $46 \%$ of cases $(n=601)[11,12]$.

Our results show three times higher APH levels in transfer patients compared to those from home. This highlights a defect of the technical platform at the level of the structures that evacuated, forced to transfer the patients either by default of diagnosis or 
by inability to take care of this complication. The efforts of the administrative authorities must therefore be continued to train staff so that they can detect and better care for such patients when they first arrive in their structures. These measures require even more the involvement of the State for the posting of qualified personnel and in sufficient number in maternity wards.

\section{Sepsis}

In our study, we did not observe any cases of puerperal infection whereas, the MOMA study showed that postpartum infection is the most common obstetric complication in West Africa $[11,12]$. The results of our study are encouraging compared to figures found in other West African countries where infections account for $10.9 \%$ of obstetric complications [12]. In Burkina Faso, $0.5 \%$ of deliveries were complicated by persistent fever, while the corresponding ratios were $1.8 \%$ in the Philippines and $3.3 \%$ in India. In Benin and Niger, puerperal infection was the least frequent with $5.4 \%$ and $3.4 \%$ of cases, respectively. Moreover, in the world, the rate of sepsis has been estimated at $4.4 \%$ of pregnancies [3]. Comparisons with other incidence studies are however difficult because most measure fever with no mention of puerperal infections.

The results obtained in our study are correlated with the general improvement of the population's hygiene conditions but also with the popularization of antibiotic therapy in patients who delivered by cesarean or vaginal delivery. These improvements appear to be related to the Safe Motherhood Initiative launched in 1987 by WHO, the United Nations Children's Fund (UNICEF), the United Nations Population Fund (UNFPA), the World Bank and all other organizations working on the agenda of maternal health, and that have placed maternal mortality at the forefront of international public health concerns [4].

\section{Dystocia}

In 2000, WHO estimated that dystocia was the second most common complication hindering $1.98 \%$ of all pregnancies [12]. In our study, dystocia was 4.6 times more common with a rate estimated at $9.3 \%$ of pregnancies. This rate is roughly the same as those found by the MOMA study in Saint-Louis (10.7\%) and Kaoloak $(7.2 \%)[11,12]$. Worldwide, the incidence of this complication was estimated at $4.6 \%$ of obstetric complications [3]. The study of dystocia comes up against a lack of standardized definition. The comparison between the studies is not easy because of the great variability of pathologies that the term dystocia encompasses.

Our work showed that dystocia was 2 times more common in primiparous patients than multiparous women and 1.5 times more common in adolescent than in adults. This highlights the harmful consequences of teenage pregnancies and the need to educate the population especially in terms of sensitization for the reduction of early marriages. Our suggestions are all the more important since dystocia was the main cause of caesarean section indication in our study, with $31.7 \%$ of cases.

\section{Ruptured uterus}

The occurrence of a RU in our study was evaluated at $0.20 \%$ of cases (43 patients). The MOMA study reported a rate of RU equal to $0.12 \%$ of pregnancies in Africa [12]. In West Africa, this complication accounted for a high rate of $12.7 \%$ of maternal deaths. In our study, the occurrence of RU was observed in 40 cases $(0.20 \%)$ of multiparous patients and 3 cases in primiparous women. The mode of admission does not seem to significantly influence the occurrence of RU because the rates are substantially similar whether it is a patient from a transfer $(0.3 \%$ or 19 cases $)$ or from her home $(0.1 \%$ or 24 cases).

The influence of the transversal presentation is clear and represents $2.5 \%$ of cases against $0.20 \%$ for cephalic cases and $0.10 \%$ for the breech presentations. This result brings to light the quality of health staff and the technical facilities because the foetal presentation must be diagnosed quickly in order to take the necessary measures to avoid the occurrence of complications. In addition, pregnancies of multiparous and adult patients should be closely monitored because RU rates are higher in their categories. The results we have obtained are probably due to the cultural habits of our population. This because, patients "accustomed" to pregnancy sometimes question the usefulness of antenatal or even hospital delivery [2].

These results put an emphasis on the importance of improving the health and information policies towards population since we have observed that RU has occurred more often in early term pregnancies $(0,40 \%$ of $\mathrm{RU}$ on early term pregnancies versus $0.20 \%$ for full term pregnancies).

\section{Conclusion}

Obstetric complications are a growing concern around the world and in sub-Saharan Africa in particular. We found that patients most affected by major obstetric complications were the primiparous women and that the most common complication is firstly dystocia, then severe pre-eclampsia and antepartum haemorrhage. The problematic of these impediments is still not well documented and reported in Africa. The mastery of the parameters favoring the occurrence of obstetric complications and their different rates of occurrence can not formally prevent the occurrence of the pathology. However, these elements obviously make it possible to carry out an increased surveillance, an adequate prevention and, finally, an optimized support. Evaluating these parameters nationally or even across the continent would reduce the incidence of major obstetric complications.

The challenge of major obstetric complications must be addressed to reduce maternal mortality and reach the third SDG by 2030. More targeted actions, towards the population, the health structure and the state, need to be put in place in the short and medium term targeting the population. In order to promote prevention and thus reduce maternal mortality, the CSPMS must maintain its level of quality of care requirements and continue its program of computerization of medical records. Only through strengthening the knowledge of the determinants of maternal complications, will the goal of reducing maternal mortality be achieved. 


\section{References}

1. USAID (2012) Sante maternelle et neonatale au Senegal: Succès et Défis Senegal. p. 80.

2. Carles G (2014) Grossesse, accouchement et cultures: approche transculturelle de l'obstétrique. Journal de Gynécologie Obstétrique et Biologie de la Reproduction 43(4): 275-280.

3. Bernis DEL (2005) La mortalité maternelle dans le monde. In: vigot d (Ed), Mise à jour en obstétrique 29: 93-132.

4. Brouwere DV, Zinnen V, Delvaux T (2012) Conduire des Revues des cas de Décès Maternels (RDM). Guide et outils pour les professionnels de la santé Londres: Fédération International de Gynécologie et Obstétrique p. 45.

5. Mandelbrot L (2006) PFC Surveillance de la grossesse normale. EMC Gynécologie-Obstétrique p. 13.

6. Organistion Mondiale DeLa Santé (2004) Au-delà des Nombres Examiner les morts maternelles et les complications pour réduire les risques liés à la grossesse p.154.

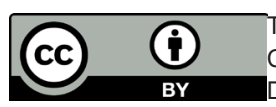

This work is licensed under Creative Commons Attribution 4.0 License DOI: $10.19080 / J G W H .2018 .13 .555864$
7. Organistion Mondiale De La Santé (2008) Classification Statistique Internationale des maladies et des problèmes de santé connexes. Dixième révision (CIM 10), Genève, p. 226.

8. Organistion Mondiale De La Santé (2015) Classification Statistique Internationale des maladies et des problèmes de santé connexes. Dixième révision (CIM 10), Canada, p. 879.

9. Organistion Mondiale De La Santé (2005) Mortalité maternelle en 2005: estimations de L'oms, L'unicef, L'unfpa et la Banque mondiale, Genève, p. 46.

10. Organistion Mondiale De La Santé (2011) Surveillance des soins obstétricaux d'urgence: manuel d'utilisation. OMS, Geneve, p. 162.

11. Ouédraogo C, Bouvier-Colle MH (2002) Mortalité maternelle en Afrique de l'ouest : comment, combien et pourquoi? Journal de Gynécologie Obstétrique et Biologie de la Reproduction 31(1): 80-89.

12. Prual A, Bouvier-Colle MH, Bernis DL, Bréart G (2000) Severe maternal morbidity from direct obstetric causes in West Africa : incidence and fatality rates. Bull World Health Organ 78(5): 593-602.

\begin{tabular}{l} 
Your next submission with Juniper Publishers \\
will reach you the below assets \\
- Quality Editorial service \\
- Swift Peer Review \\
- Reprints availability \\
- E-prints Service \\
- Manuscript Podcast for convenient understanding \\
- Global attainment for your research \\
- Manuscript accessibility in different formats \\
( Pdf, E-pub, Full Text, Audio) \\
- Unceasing customer service \\
Track the below URL for one-step submission \\
https://juniperpublishers.com/online-submission.php \\
\hline
\end{tabular}

